turning over the patient on his back, and following up the examination to the left hip, it was soon obvious that he was suffering from dislocation of the left hip into the foramen ovale. The head of the femur was plainly felt in the perinoum, and the trochanter had fallen in. Chloroform was administered, and the dislocation was soon reduced in the manner laid down by the same great authority, Sir Astley Cooper. The only singular part of this case is, that the pain suffered was attributed to the opposite limb, which was to some extent contused, and the leg fractured. This is, too, an accident of not very frequent occurrence. I have met with one only of the same description before.

Both these cases are doing well.

Tir Caradoc, Taibach, April 11th, 1ミ5-1.

\section{CASE OF POISONING BY CHLOROFORM.}

By F. H. HARTSHoRNE, Esq.

Or March 26th, 1854, about three o'clock P.M., a child, four years of age, the son of a druggist, drank from one to two drachms of chloroform, from a bottle containing about half an ounce, which had been left on a dressing-table. Another bottle stood by, in which was a mixture of rhubarb and magnesia, some of which the father thinks the child mixed with the chloroform in a tea-cup, and drank, "the child being a great mimic", and having frequently scen his father take the latter mixture. He then carried the cup down stairs, and said, "Papa, I have taken some medicine"; and walked into the kitchen and back; then he complained of pain in the epigastric region, and desired to defecate. He sat on a vessel a few moments, and again rose, without having had an evacuation. Being subject to pain in his bowels, his mother laid him across her knees, and began friction with her hand on his abdomen, when he exclaimed, "Oh mamma, my head", and immediately his head dropped, and eyes "set". The father directly gave him some cold water, a little of which, he thinks, was swallowed. The apprentice now discovered he had taken chloroform, and the father ran with him in his arms a short distance, to the surgery of Mr. Richard Thursfield, and the child romited on the road. A period of about ten minutes elapsed from taking the chloroform until insensibility commenced; in another twenty minutes, I arrived at Mr. Thursfield's surgery, and then the child's pupils were contracted, his breath smelt very strongly of chloroform, and his breathing was laborious; the pulse was quick and full, the face pale, and the extremities rather cold. He vomited twice afterwards, but the food was not readily expelled from the pharynx and mouth, and once he appeared to be dying of asphyxia; but he at length made some gasping inspirations, and the former laborious respiration was again established. This we discovered was caused by a large piece of undigested food closing the aperture of the glottis, and which was removed from the pharynx with the finger. No attempt at deglutition could be excited; the pupils became alternately contracted and dilated; the face livid and pale; the extremities warm and cold; the pulse at one time quick and full, at another scarcely perceptible; at length strabismus came on, the eyes being turned upwards; the breathing became more and more stertorous; and he died in a state of profound coma, three hours after taking the fatal dose.

No post mortem examination was made. An inquest was held on the body, at which no medical evidence was given; the verdict being, that the deceased died from taking chloroform.

The parents state that they kept the body eight days. During the whole of that time, the rigor mortis continued, and the face, though pale when the child expired, had its usual florid colour.

I have hitherto said nothing about the treatment. It consisted in attempts to administer an emetic of sulphate of zinc, and to use the stomach-pump, and in the application of sinapisms to the calves of the legs, ammonia to the nostrils, and leeches to the temples. Artificial respiration was tried, and lastly a warm bath.

Bromely, April 12th, 1834.

\section{CASE OF POISONING BY ONE-TWENTIETH} OF A GRAIN OF OPIUM.

\author{
By EDWARD SMITH, M.D., LL.B.
}

[Read before the Medical Society of London, April 8th, 1854.].

The following case is offered, not as being unique, but in compliance with the good rule of placing on record rare and important cases. Very few authentic cases are met with in our works on medical jurisprudence, in which death has resulted from so small a quantity of opium as that which is contained in one drop of laudanum; but I find from conversation with my medical friends, that such instances have occurred; and, moreover, the deputy-coroner, in his address to the jury in this case, affirmed that he had recently held an inquest under such circumstances. Instances are very numerous in which serious results have followed the administration to infants of doses varying from onc-twentieth to one-eighth of a grain ; and these: alone might serve to suffice as a caution against the exhibition of this drug in any quantity in cases where the patient is only a few days, or it may be weeks, old.

CASE. The little patient was the son of Italian parents, and was five days old (the sixth day after its birth) when the opium was administered. It had cried much during the. preceding nights; and, as the bowels had not acted freely, I directed the nurse to administer small doses of castor oil. This, I bclieve, was very inefficiently performed, owing perhaps to the inability of the parents or the nurse to understand or speak English; and therefore I objected to give soothing medicine as they suggested, and again recommended the castor oil. At length the French vurse sought. the shop of a French drug and coffee-house keeper, and obtained a syrup, of which half a tea-spoonful was to beadministered every two or three hours, until the child became quiet. As an evidence of carelessness on the part of the Frenchman, I may state that no label of any kind was placed upon the bottle, and that the bottle itself was ten times too large for the quantity of medicine supplied. The nurse mentioned the age of the infant, and left it to the discretion. of the druggist to supply the required remedy. The first and only dose was given at about half-past 10 P.M., on the sixth day after its birth, and within half an hour induced. the usual symptoms of poisoning by opium. The cries ceased; the features bccame pale; the jaw fell ; the respirations became laborious and irregular; and at length coma supervened. The nurse had by this time left the house, so that the parents had the sole care of the child. They, after a time, became scriously alarmed at the above-mentioned symptoms, and at the fact that the child ceased to take the breast; and during the night they called an English lady resident in the house, who was also familiar with the French language. They remained at the side of the child during the night, and deferred sending for me until the morning, since I lived at a distance from their habitation. When I reached the house, at half-past 9 A.M., on the seventh day from the birth of the infant, I found it perfectly insensible. Pinching the skin, or tickling the soles of the feet, caused no muscular movement; the pupil was fixed and contracted; the lung-motion was insensible to the touch; the face was pale, and the features natural; the limbs were relaxed, and without any movement, except a very rare and occasional spasmodic motion of the upper extremities; once or twice it also moved its lower lip, and the eyes opened spasmodically. The child had passed both fæces and urine, in small quantity, into the napkin, which had not been removed. The respiration on my first seeing it was almost suspended: so much so, that I had no doubt as to the rapid dissolution of the patient; but after a time it recovered, and became more rapid than natural. This latter condition remained for a few minutes; but at length gave way to the former condition of suspended respiration. These opposed states were renewed in succession until pear to the period of its death. The pulsations of the heart bore an exact. relation to the state of the respiration. When the latter was rapid, the pulsations were regular and tolerably firm, 